\title{
RECURRENT POST CRICOID WEB IN PLUMMER VINSON SYNDROME - IS IT MALIGNANCY NEXT?
}

M. Panduranga Kamath ${ }^{1}$, Vijendra Shenoy S2, Suresh Shenoy ${ }^{3}$, Vishnu Prasad K.P ${ }^{4}$, Aswin Mukundan ${ }^{5}$

\section{HOW TO CITE THIS ARTICLE:}

M Panduranga Kamath, Vijendra Shenoy S, Suresh Shenoy, Vishnu Prasad KP, Aswin Mukundan. "Recurrent post cricoid web in plummer Vinson syndrome - is it malignancy next?" Journal of Evolution of Medical and Dental Sciences 2013; Vol2, Issue 35, September 2; Page: 6748-6753.

ABSTRACT: Plummer-Vinson syndrome is known as the association of postcricoid dysphagia, upper oesophageal web, and iron deficiency anaemia. Although correction of iron deficiency may result in resolution of dysphagia and sometimes disappearance of the webs, dilation therapy is usually necessary to remove webs and relieve dysphagia. We report a rare case of Plummer-Vinson syndrome with recurrent post cricoid web. Patient had undergone balloon dilatation for the web three year back and was symptom free for three years. The patient presented this time with significant dysphagia, sideropenia, angular stomatitis and generalised weakness. Our patient had occasional choking and aspiration episodes at eating and endoscope did not pass through at the level of the upper oesophagus. Patient's barium swallow revealed the presence of webs in part of the post-cricoid region. Patient was treated with oesophageal balloon dilation, blood transfusion and iron supplementation. The patient is put on regular follow-up.

KEYWORDS: Plummer Vinson syndrome, dysphagia, Post cricoid web, Iron deficiency anaemia, Angular stomatitis

INTRODUCTION: Plummer-Vinson or Paterson-Kelly syndrome presents as a classical triad of dysphagia, iron-deficiency anaemia and oesophageal webs [2,3]. Exact data about epidemiology of the syndrome are not available; the syndrome is extremely rare. Most of the patients are white middleaged women, in the fourth to seventh decade of life but the syndrome has also been described in children and adolescents. The dysphagia is usually painless and intermittent or progressive over years, limited to solids and sometimes associated with weight loss. Symptoms resulting from anaemia (weakness, pallor, fatigue and tachycardia) may dominate the clinical picture. Additional features are glossitis, angular cheilitis and koilonychia. Enlargement of the spleen and thyroid may also be observed. One of the most important clinical aspects of Plummer-Vinson syndrome is the association with upper alimentary tract cancers $[4,5,6]$. Etiopathogenesis of Plummer-Vinson syndrome is unknown. The most important possible etiological factor is iron deficiency. Other possible factors include malnutrition, genetic predisposition or autoimmune processes. PlummerVinson syndrome can be treated effectively with iron supplementation and mechanical dilation. In case of significant obstruction of the oesophageal lumen by oesophageal web and persistent dysphagia despite iron supplementation, rupture and dilation of the web are necessary. Since Plummer-Vinson syndrome is associated with an increased risk of squamous cell carcinoma of the pharynx and the oesophagus, the patients should be followed closely.

CASE REPORT: 41 year old female who was a known case of Plummer Vinson syndrome on constant follow up and iron supplementation presented to us with complaints of dysphagia to solids since 2 months, generalised weakness, easy fatigability, decreased appetite and lesions over the angle of the 
mouth. She had similar complaints three years back and was diagnosed to have Plummer Vinson syndrome with oesophageal web and iron deficiency anaemia for which dilatation was done and she was symptom free for the last 3 years. This recent episode was according to the patient more severe and with more symptoms. Her menstrual history was normal with regular cycles of 25-28 days duration with moderate flow for 3-4 days.

Patient physically looked emaciated, severely dehydrated, pale and lethargic. She weighed 45 $\mathrm{kg}$ and her temperature (oral) was $37^{\circ} \mathrm{C}$. Blood pressure was $100 / 60 \mathrm{~mm}$ of $\mathrm{Hg}$; Pulse $88 / \mathrm{minute}$ and respiration was 18/minute. There was bilateral angular stomatitis with epithelial crust on the lips (fig.1).The skin appeared generally dry. There was a small discrete jugulo-digastric node palpable on the right side of the neck. Chest auscultation revealed normal heart sounds. The abdomen was soft, non-tender and the liver, spleen and kidneys were not palpably enlarged. Intraorally the oral mucosa was dry.

On the first day of admission a rehydration measures were started with close monitoring of fluid input and output. She was further evaluated with a complete haemogram which showed haemoglobin to be $8.2 \mathrm{~g} \%$ confirming the presence of anaemia. Peripheral smear picture was that of microcytic hypochromic anaemia with anisopoikilocytosis suggestive of iron deficiency anaemia. Ultrasound abdomen done was normal. Subsequently a Barium swallow X-ray oesophagus was done which showed an oesophageal web at the level of the post cricoid (fig.2).She was then posted for upper gastrointestinal flexible endoscopy and web dilatation and the procedure was successfully completed (fig. 3). Along with the procedure, biopsy was taken from the lesion so as to rule out malignant transformation. It was reported as negative for malignant cells. Patient recovered well. A repeat barium swallow was done after 6 weeks which confirmed successful dilatation and absence of oesophageal pathology (fig.4). During the course of hospital stay she was transfused with 3 bottles of cross matched whole blood and at the time of discharge her haemoglobin was $12.7 \mathrm{~g} \%$. She is now on constant followup every 2 months and is put on iron supplementation and there is no recurrence till date.

DISCUSSION: In 1919, Patterson and Kelly independently described a clinical state (the PattersonKelly Syndrome) with which the names of Plummer and Vinson were later associated in the United States [1]. The syndrome which is the association of dysphagia with anaemia was earlier recognized by Plummer around 1914. Vinson described two additional cases later under the term "hysterical dysphagia". Plummer Vinson Syndrome (PVS) is a rare disease which affects mainly white women and it is characterized by dysphagia, iron deficiency and presence of superior oesophageal web ${ }^{[8,}$ 9]. The age range is between 40-70years; however PVS has also been described in children and adolescents [10,11].

The pathogenesis of PVS is unknown. The most important possible etiological factor is iron deficiency. This theory is primarily based on the finding that iron deficiency is a part of the classic triad of PVS together with dysphagia and oesophageal webs and that dysphagia can be improved by iron supplementation [9]. Another opinion believes that it is unlikely that iron deficiency anaemia is the sole explanation for the development of the webs, because webs are found in only approximately $10 \%$ of patients with iron deficiency anemia [11]. Other etiologic factors including malnutrition, genetic predisposition, or even auto-immune process have been proposed [9]. 


\section{CASE REPORT}

Most commonly, patient first have dysphagia to solids, but over time, symptoms can progress to involve dysphagia to liquids as well [10]. According to Novacek the dysphagia is usually non painful, and its progression can eventually lead to weight loss ${ }^{[14]}$.

PVS has been identified as a risk factor for developing squamous cell carcinoma of the upper gastrointestinal tract [13]. Three to fifteen percent of the patients with PVS, mostly women between 15-50 years of age have been reported to develop oesophageal or pharyngeal cancer [12]. According to Kim et al[15] PVS is thought to be precancerous because squamous cell carcinoma of hypo pharynx, oral cavity or oesophagus takes place in $10 \%$ of those patient suffering from this malady. The incidence of cancer of the tongue while comprising $25-50 \%$ of all intra-oral cancers is relatively uncommon among women except in certain geographical localities chiefly Scandinavian countries, where it has been associated with pre-existing PVS[3]. We would like to emphasize the need to take biopsy from the lesion during upper gastrointestinal scopy and, if need be, dilatation every 2 months even though the patient is symptom free.

The complete triad of PVS include cervical dysphagia, iron deficiency anaemia, angular stomatitis and post cricoid web.The patient we are reporting presented with all three. A barium swallow study is advised for the detection of a web, and other method will be an upper gastrointestinal endoscopy [9, 11]. The treatment of PVS is hinged on the clarification of the cause of iron deficiency, if a patient demonstrates one and the rupture of and dilation of the web if it causes obstruction. The prognosis for the PVS is generally good from the standpoint that two of the triads (anaemia and dysphagia) can be effectively treated. In case of an associated squamous cell carcinoma of the hypo pharynx or upper oesophagus the prognosis worsens dramatically [9].

The incidence of recurrence of oesophageal webs in a known case of PVS is rarely seen. This is more often related to poor compliance of the patient to follow-up and treatment or absence of iron supplementation from the time the disease was diagnosed. Persistence of Iron deficiency anaemia may lead to recurrence [9]. However, large clinical series suggested that for many patients iron deficiency is neither a necessary nor a sufficient cause of web formation [7]. In very rare occasions patients can have recurrent webs even with adequate iron supplementation; which we consider is the case with our patient.

CONCLUSION: Although Plummer Vinson syndrome is a rarity nowadays a high degree of suspicion aided with appropriate investigation is essential to diagnose the condition. Importance of early diagnosis is again emphasised by the fact that most the symptoms can be treated by simple procedures and recurrence can be prevented by putting the patient on regular follow-up and iron supplementation. As is seen with our case, balloon dilatation is a very effective and complete modality of treating oesophageal web. Patient should be put on regular follow-up with upper GI scopy with or without dilatation and biopsy every 2 months. Through this case report we would like to emphasize importance of iron supplementation through diet as it is more patient friendly and we can ensure adequate iron is supplemented even when patient is non-compliant to medications as well as the need for regular follow up of these patients in order to prevent morbidity and for early diagnosis of malignancy, 


\section{REFERENCES:}

1. Paterson Dr. A clinical type of dysphagia. J LaryngolRhinolOtol34:289-91

2. Sabiston and Spencer. Surgery of the chest, 5th edn. 1990. p. 881

3. Herbella FA, Matone J, Del Grande JC. Eponyms in oesophageal surgery, part 2. Dis Esophagus 2005;18:4-16

4. Messmann H.Squamous cell cancer of the oesophagus. Best Pract Res ClinGastroenterol 2001; 15:249-265.

5. Suzan, M.M. Syndrome of anaemia, glossitis and dysphagia. Arch Intern Med 51:1-21

6. Anderson SR, Sinacori JT. Plummer-Vinson syndrome heralded by post cricoid carcinoma. Am J Otolaryngol 2007;28:22-24

7. Dantas RO. Iron deficiency and dysphagia. Am J Gastroenterol 1999;94:3072-3

8. Ben Gamra O, Mbarek C, Mouna C, Zribi S, Zainine R, Hariga I et al. Plummer Vinson Syndrome. Tunis Med 2007;85:402-4

9. Novacek G. Plummer Vinson Syndrome. Orphanet. J Rare Dis 2006; 1: 36

10. Mansell NJ, Jani P, Bailey CM. Plummer-Vinson Syndrome a rare presentation in a child. J. LaryngolOtol 1999;113:475-6

11. Medrano M. Dysphagia in a Patient with RA and iron deficiency anaemia. Medscape General Medicine 2002;4

12. Godina J, Wong PW. A triad of troubling findings. Plummer Vinson Syndrome. Postgrad Med 2000;108:109-10

13. Huffman RM, Jaffe PE. Plummer-Vinson Syndrome. A case report and literature review. Arch Intern Med 1995:155;2008-11

14. Novacek G. Plummer-Vinson Syndrome. Orphanet Encyclopedia 2005.

15. Kim KH, Kim MC, Jung GJ. Gastric cancer occurring in a patient with Plummer-Vinson Syndrome: a case report World J Gastroenterol 2005; 11:7048-50.

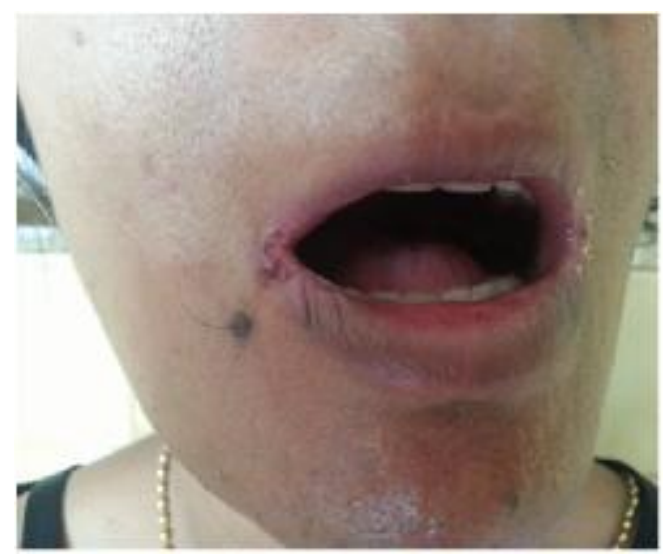

Figure 1: Patient presented with angular stomatitis 


\section{CASE REPORT}

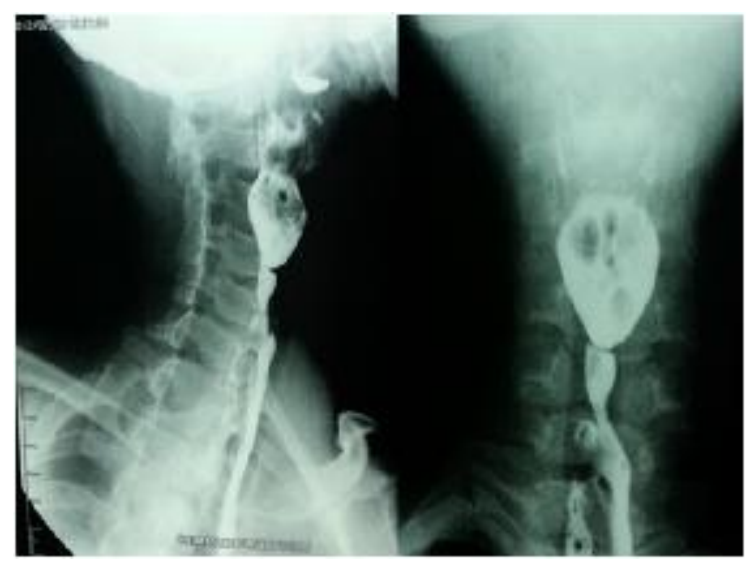

Figure 2: Barium swallow X-ray showing oesophageal web.

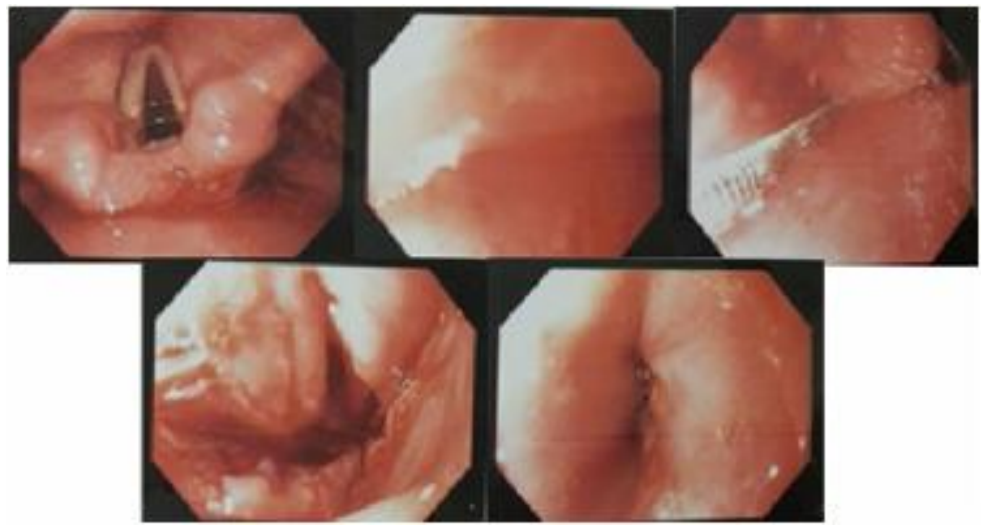

Figure 3: Balloon dilatation of the web

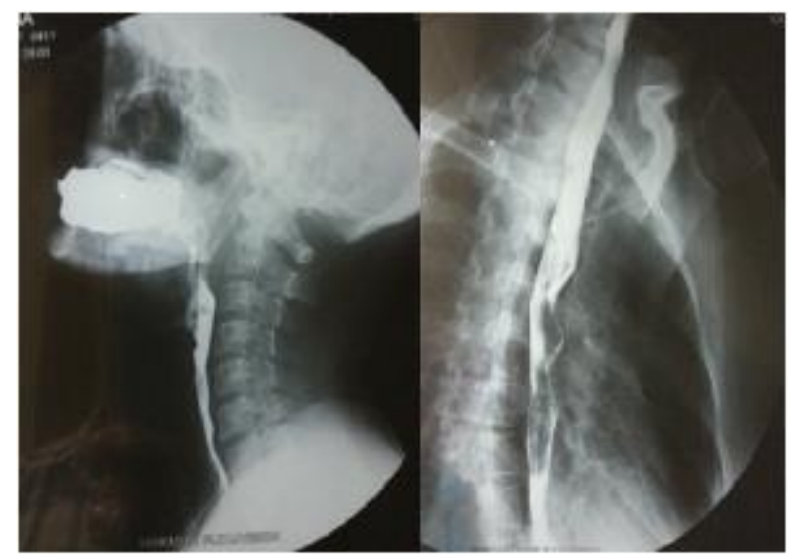

Figure 4- Post-dilatation barium swallow X-ray 


\section{AUTHORS:}

1. M Panduranga Kamath

2. Vijendra Shenoy S.

3. Suresh Shenoy

4. Vishnu Prasad K.P.

5. Aswin Mukundan

\section{PARTICULARS OF CONTRIBUTORS:}

1. Professor, Department of Otorhinolaryngology and Head and Neck Surgery, Manipal University.

2. Associate Professor, Department of Otorhinolaryngology and Head and Neck Surgery, Manipal University.

3. Associate Professor, Department of Otorhinolaryngology and Head and Neck Surgery, Manipal University.
4. Senior Resident, Department of Otorhinolaryngology and Head and Neck Surgery, Manipal University.

5. Resident, Department of Otorhinolaryngology and Head and Neck Surgery, Manipal University.

\section{NAME ADRRESS EMAIL ID OF THE CORRESPONDING AUTHOR:}

Dr. Vijendra Shenoy S,

Department of Otolaryngology,

Kasturba Medical College Hospital,

Attavar, Mangalore - 575 001,

Manipal University, Karnataka State, India.

Email - drvijendras@gmail.com

Date of Submission: 24/08/2013.

Date of Peer Review: 26/08/2013.

Date of Acceptance: 27/08/2013.

Date of Publishing: 29/08/2013 